\title{
Miller-Dieker syndrome
}

INSERM

\section{Source}

INSERM. (1999). Orphanet: an online rare disease and orphan drug data base. Miller-

Dieker syndrome. ORPHA:531

Miller-Dieker Syndrome (MDS) is a contiguous gene deletion syndrome of chromosome 17p13.3, characterised by classical lissencephaly (lissencephaly type 1) and distinct facial features. Additional congenital malformations can be part of the condition. 